\title{
P385: Microbial contamination of dental unit waterline system (DUWS)
}

\author{
F Abdul Razak', RB Ahmad ${ }^{2 *}$, WHA Wan Harun' ${ }^{1}$ CS Chua ${ }^{1}$ \\ From 2nd International Conference on Prevention and Infection Control (ICPIC 2013) \\ Geneva, Switzerland. 25-28 June 2013
}

\section{Introduction}

The high presence of microbes in water delivered from dental chair unit (DCU) is of concern as it has been associated with high concentration of endotoxin. The American Dental Association (ADA) recommended a microbial population of $200 \mathrm{cfu} / \mathrm{mL}$ as acceptable in DCU water.

\section{Objectives}

The study aimed to evaluate the sanitary level of water from DCUs in a teaching dental clinic and relate the finding to the sterilizing/infection control practices by the clinical personnel.

\section{Methods}

The total microbial load of water samples collected from thirteen DCUs was determined using conventional microbiological methods. Based on the count of colonies formed (cfu) on heterotrophic media plates following an incubation period, the microbial load of the samples was determined in colony forming units per milliliter of water $(\mathrm{cfu} / \mathrm{mL})$. Plate counts to determine the presence of pathogenic contaminants such as, total coliforms count, faecal coliforms count, Escherichia coli count, faecal streptococci count and Pseudomonas aeruginosa were carried out using techniques proposed in the Standard Methods for Examination of Water and Wastewater. The presence of other microorganisms was determined using PCR technique.

\section{Results}

The $\mathrm{pH}$ of DCU water in the clinic was found to be slightly acidic at $\mathrm{pH}$ 5.4-5.5 and the average water temperature was at $23{ }^{\circ} \mathrm{C}$. The water delivered from all the
DCUs was found free of all the pathogens mentioned. The water was however found loaded with other bacteria at varying population: Sphingomonas rhizogenes (17.9\%), Sphingomonas dokdonesis (79.5\%), Sphingomonas mucosissima $(1.1 \%)$ and Methylobacterium radiotolerans $(1.5 \%)$. As routine infection control practice, only distilled water is being run in the DCUs. Prior to usage the distilled water was contained in storage bottles before it is dispensed into individual reservoir of each DCU. Since every DCU has bypassed the main connection to municipal water supply, it is thus suggested that the introduction of contaminant may have occurred during storage.

\section{Conclusion}

DCU water in the clinic under study was highly contaminated with microbes and failed to meet recommendation by the ADA. The thorough revise of the infection control practice in the clinic is strongly required.

\section{Disclosure of interest}

None declared.

\section{Author details}

${ }^{1}$ Oral Biology, University of Malaya, Kuala Lumpur, Malaysia. ${ }^{2}$ University

Malaya Dental Center (PPgUM), University of Malaya, Kuala Lumpur, Malaysia.

Published: 20 June 2013

doi:10.1186/2047-2994-2-S1-P385

Cite this article as: Razak et al:: P385: Microbial contamination of dental unit waterline system (DUWS). Antimicrobial Resistance and Infection Control 2013 2(Suppl 1):P385.

${ }^{2}$ University Malaya Dental Center (PPgUM), University of Malaya, Kuala

Lumpur, Malaysia

Full list of author information is available at the end of the article

C 2013 Razak et al; licensee BioMed Central Ltd. This is an Open Access article distributed under the terms of the Creative Commons 